\title{
ENGEVISTA
}

Página da revista: http://www.uff.br/engevista/seer/

\section{Simulação do controle de uma coluna de destilação descontínua utilizando o Scilab}

\author{
George Simonelli ${ }^{1}$ \\ Breno Frigini Mai ${ }^{2}$ \\ Deiver Robson Saccani Vichelo ${ }^{3}$ \\ Humberto Frigini De Marchi ${ }^{4}$ \\ Romero Florentino de Carvalho ${ }^{5}$
}

Resumo: Controlar um processo significa manter as variáveis de interesse operando em valores préestabelecidos por meio de um controlador. O ajuste desses controladores é comumente realizado através da simulação computacional, a qual fundamenta-se na utilização de um software. A utilização de softwares para a realização de simulações é uma tendência que pode ser observada atualmente tanto na área industrial, quanto na área acadêmica. O Scilab é um exemplo de software livre desenvolvido para o uso acadêmico, o qual apresenta uma excelente capacidade lógica de programação. Neste trabalho é usado o utilitário Xcos, do Scilab, na análise da estabilidade de um sistema de controle em malha aberta (sem controlador) e em malha fechada (com controlador P, PI e PID) de uma coluna de destilação descontínua real. Os dados referentes a essa coluna de destilação foram obtidos de uma dissertação de mestrado da UFSM. O sistema de controle em malha aberta foi avaliado com base no conceito dos polos de uma função de transferência, enquanto que o sistema de controle em malha fechada foi avaliado por meio do método de Routh e da substituição direta. Os controladores P, PI e PID foram ajustados através do método de Ziegler e Nichols. Uma análise gráfica do comportamento da temperatura do pré-condensador em função da vazão de vapor, da vazão de água e da razão de refluxo da coluna de destilação permitiu concluir que o controlador PI foi capaz de estabilizar a temperatura do précondensador no valor desejado de 351,5993 K em pouco tempo. Além disso, foi possível eliminar o offset.

\footnotetext{
${ }^{1}$ UFBA - Universidade Federal da Bahia

${ }^{2}$ FAACZ - Faculdades Integradas de Aracruz

${ }^{3}$ FAACZ - Faculdades Integradas de Aracruz

${ }^{4}$ FAACZ - Faculdades Integradas de Aracruz

${ }^{5}$ UFES - Universidade Federal do Espírito Santo
} 
Palavras-chave: Software, Xcos, controlador, operação unitária.

\begin{abstract}
A process control means to maintain the operating variables of interest at pre-established values by means of a controller. The adjustment of these controllers is commonly performed by computer simulation which is based on use of a software. The use of software to perform simulations is a trend that can be observed today both in the industrial area, and in academia. Scilab is an open source example developed for academic use, which has an excellent ability logic programming. This paper used the Xcos utility, Scilab, the analysis of the stability of a control system in open loop (without driver) and closed loop (P-controller, PI and PID) of a real batch distillation column. Data for this distillation column were obtained from a master's thesis, UFSM. The open loop control system was evaluated based on the concept of the poles of a transfer function, while the control closed loop system was evaluated by the Routh method and direct replacement. P controllers, PI and PID were set by Ziegler and Nichols method. A graphical pre-condenser temperature behavior analysis function of vapor flow rate, water flow rate and reflux ratio of distillation column concluded that the PI controller was able to stabilize the temperature of the pre-condenser to the desired value of $351.5993 \mathrm{~K}$ shortly. Moreover, it was possible to eliminate offset.
\end{abstract}

Keywords: Software, Xcos, controller, unit operation. 


\section{Introdução}

A simulação computacional consiste na utilização de certas técnicas matemáticas em computadores, as quais permitem avaliar o funcionamento de um determinado processo (FREITAS, 2008). Em outras palavras, é o estudo do comportamento de um processo a partir de modelos matemáticos que descrevem o mesmo. A simulação é hoje uma ferramenta muito importante para os engenheiros químicos, pois permite analisar a estabilidade e o comportamento do processo e controlá-lo (MENEGUELO, 2007).

Controlar um processo significa manter uma certa variável em um determinado valor desejado (setpoint) ou em um valor próximo dele. O controle de processo é a técnica de manter variáveis de um processo, isto é, qualquer grandeza ou condição do processo que seja passível de variação, em valores predeterminados a partir de um controlador de processo. O controlador é o equipamento responsável pelo controle do processo, o qual atua em função do erro existente entre o valor desejado (setpoint) e o valor medido pelo sensor (medidor). Atualmente, existe uma enorme variedade de controladores, cada um com suas vantagens e desvantagens (BAYER; ARAÚJO, 2011).

Os principais controladores encontrados na prática são os controladores $\mathrm{P}$ (Proporcional), PI (Proporcional e Integral) e PID (Proporcional, Integral e Derivativo). De todos eles, o controlador PID é o mais tradicional na indústria. A sua popularidade, sobretudo em processos que envolvem a destilação, se deve à simplicidade no ajuste de seus parâmetros (CAMPOS; TEIXEIRA, 2010).

A destilação é uma técnica de separação bastante utilizada na indústria e baseia-se no fato de os elementos constituintes da mistura possuírem diferentes temperaturas de ebulição. Assim, ao fornecer calor à mistura, consegue-se preferencialmente vaporizar os componentes mais voláteis, que são condensadas no topo da coluna de destilação, enquanto os menos voláteis tendem a permanecer na fase líquida e no fundo da coluna de destilação (FOUST et al., 2008). A destilação é comumente classificada em destilação contínua e destilação descontínua. Dentre elas, a descontínua é a mais antiga e, hoje em dia, é bastante utilizada nas indústrias alimentícia, bioquímica, farmacêutica e outras, devido ao seu baixo custo operacional e sua versatilidade (KETZER, 2013).

O principal objetivo de uma coluna de destilação descontínua é separar uma mistura nos diversos componentes que a compõem, assegurando a qualidade ou a composição desejada para os mesmos (CAMPOS; TEIXEIRA, 2010). Nesse sentindo, os simuladores computacionais constituem uma importante ferramenta para as indústrias, pois eles auxiliam no controle da qualidade dos produtos e permitem que sejam realizados estudos em seus processos que provavelmente não seriam possíveis em uma unidade industrial, em virtude de fatores econômicos ou de segurança (MENEGUELO, 2007). 
ISSN: $1415-7314$

ISSN online: $2317-6717$

Com o passar dos anos, diversos trabalhos acadêmicos acerca de colunas de destilação foram elaborados e comtemplaram as áreas de modelagem, simulação e controle desses equipamentos (STAUDT, 2007).

Em sua dissertação, Cunha (1996) desenvolveu um sistema de controle adaptativo (sistema de controle capaz de modificar o seu comportamento em consequência de uma perturbação) baseado na manipulação da razão de refluxo para a destilação descontínua do n-hexano e npentano, objetivando o controle da composição do destilado (produto de topo) dentro de uma especificação desejada. Para isso, ele utilizou um software de simulação para analisar o sistema de controle desenvolvido a partir do uso de um controlador Proporcional e Integral (PI). O método de ajuste adotado para a sintonia do controlador PI foi o método de Cohen e Coon.

Por sua vez, Bravo (2005) abordou o desenvolvimento de um simulador protótipo e a aplicação de controle preditivo (sistema de controle capaz de fornecer uma previsão futura com base na situação atual da planta) baseado em modelo para a destilação de uma planta piloto. $\mathrm{O}$ simulador desenvolvido por ele foi implementado no software HYSYS, o qual permite ao usuário implementar diversas configurações de controle considerando controladores PID e controladores preditivos multivariáveis. Os resultados obtidos, segundo ele, estão em concordância com os resultados encontrados na literatura sobre as estratégias utilizadas para o controle de colunas de destilação.

Barroso-Muñoz, Hernández e Ogunnaike (2007) utilizaram o método de Ziegler e Nichols no ajuste de um controlador PI usado em um sistema de controle de uma coluna de destilação reativa. O controlador PI foi usado com o objetivo de controlar a composição do destilado a partir da manipulação da razão de refluxo da coluna de destilação. Segundo ele, o método de Ziegler e Nichols foi bastante eficaz e apresentou bons resultados.

Adel, Elamvazuthi e Hanif (2009) compararam alguns métodos de ajuste de controladores, como o método de Ziegler e Nichols, Cohen e Coon e ITAE (Integral of Time multiplied by Absolute of the Error) utilizando um sistema de controle de uma coluna de destilação binária usada na separação de água e metanol. Para isso, utilizou um controlador PI. Segundo os autores, o melhor método de ajuste foi o ITAE e o pior foi o método de Cohen e Coon.

O Scilab é um software distribuído gratuitamente através da Internet e não necessita de licença para a sua utilização, cópia e distribuição. Hoje em dia, é bastante utilizado nas áreas acadêmicas e industriais (CAMPOS, 2010; PIRES, 2014). Entretanto, estudos introdutórios deixaram claro que não há na literatura consultada, até o presente momento, trabalhos acerca de modelagem, simulação e controle de colunas de destilação descontínua que utilizam o Scilab. Diante disso, o presente trabalho objetiva utilizar o software Scilab no controle de uma coluna de destilação descontínua a partir de dados reais retirados da dissertação de mestrado "Modelagem, simulação e controle de uma coluna de destilação descontinua apropriada à produção de etanol em pequena escala" de Felipe Ketzer (2013). 
Para isso, serão calculados os polos das funções de transferência propostas por Ketzer (2013) para as variáveis manipuladas vazão de vapor, vazão de água e razão de refluxo, para a análise da estabilidade do sistema de controle em malha aberta. Em seguida, serão utilizados os métodos de Routh e da substituição direta para a análise da estabilidade do sistema de controle em malha fechada com os controladores P, PI e PID. Posteriormente, esses controladores serão ajustados de acordo com o método de Ziegler e Nichols do ganho último $\left(\mathrm{K}_{\mathrm{U}}\right)$ e período último $\left(\mathrm{P}_{\mathrm{U}}\right)$ e servirão de base para a escolha da melhor estratégia de controle para a temperatura do précondensador da coluna de destilação estudada, a qual deve ser mantida no valor de 351,5993 K (setpoint) para que não haja a formação de azeótropo.

\section{Metodologia de simulação computacional}

Para realização da simulação computacional do controle de uma coluna de destilação descontínua com o Scilab, utilizaram-se dados de uma coluna estudada por Ketzer (2013) na Universidade Federal de Santa Maria (UFSM).

Trata-se de uma coluna de destilação descontínua utilizada na produção de etanol hidratado com concentração de 95,1 a 96\% v/v a partir da separação da mistura binária etanol-água (solução hidroalcóolica). A coluna de destilação é composta por um destilador (refervedor), 20 pratos, um pré-condensador (condensador parcial) e um condensador (condensador total).

Na Figura 1 é apresentado um esquema simples da coluna de destilação descontínua citada. Observa-se que há três variáveis passíveis de manipulação: a vazão de vapor, a vazão de água e a razão de refluxo.

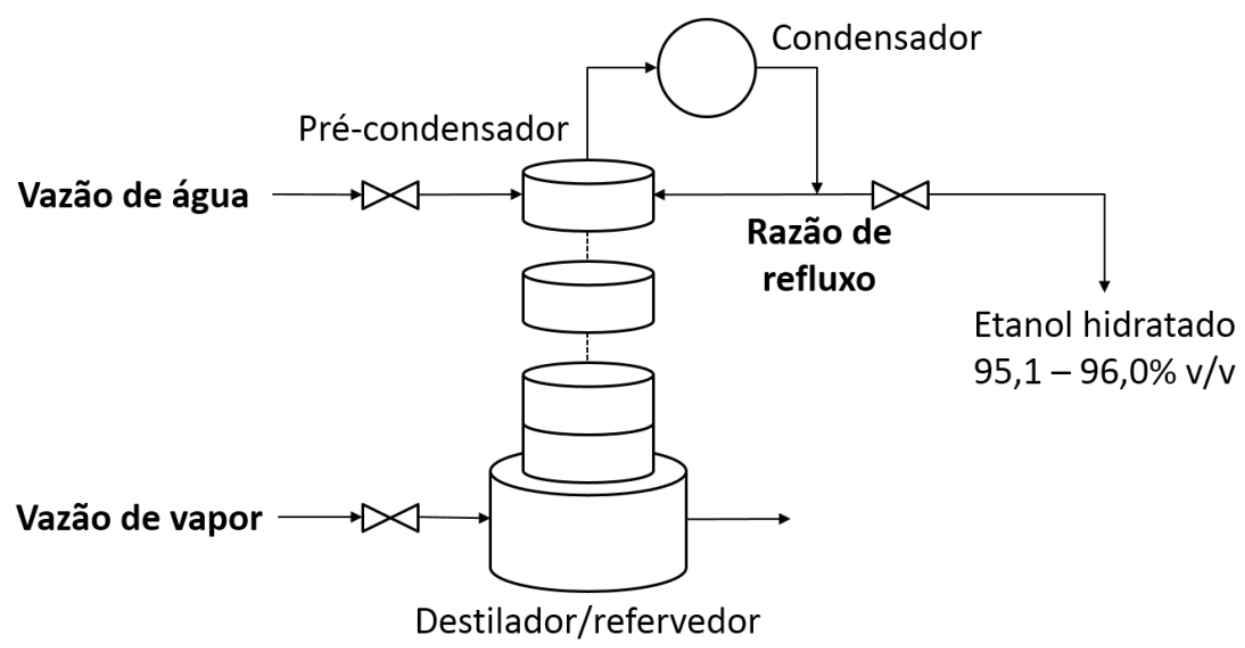

Figura 1: Esquema da coluna de destilação descontínua. Fonte: Adaptado de Ketzer (2013).

O destilador (refervedor), localizado na base da coluna de destilação (Figura 1), armazena até 600 litros de solução hidroalcóolica e é aquecido mediante a adição de vapor através de uma 
ISSN: $1415-7314$

ISSN online: $2317-6717$

serpentina. O controle de sua temperatura é feito por meio da manipulação da vazão de vapor que adentra o destilador.

Já o pré-condensador consiste em um condensador parcial e objetiva controlar a vazão de destilado que deixa a seção de retificação da coluna de destilação e segue para o condensador. $\mathrm{O}$ controle de sua temperatura é feito mediante a manipulação da vazão de água que adentra o précondensador.

Ao deixar o condensador, parte do etanol hidratado retorna à coluna de destilação como líquido refluxado e parte é armazenado como produto final (etanol hidratado com concentrações entre 95,1 e $96 \%$ v/v). Dessa maneira, o controle da razão de refluxo é feito indiretamente por meio da válvula de retirada de produto final.

De posse das variáveis manipuladas (vazão de vapor, vazão de água e razão de refluxo) e da variável controlada (temperatura do pré-condensador), Ketzer (2013) propôs através de uma modelagem empírica os seguintes modelos matemáticos para o controle da temperatura do précondensador (Tabela 1).

Tabela 1: Funções de transferência propostas para destilação estudada.

\begin{tabular}{cc}
\hline Variável manipulada & Função de transferência \\
\hline Vazão de vapor & $G_{V}(s)=\frac{0,0004657 s+1,361 \times 10^{-7}}{s^{2}+0,3096 s+8,013 \times 10^{-10}}$ \\
Vazão de água & $G_{A}(s)=\frac{-1,266 s^{3}-9,229 s^{2}-20,4 s-74,26}{s^{4}+6,451 s^{3}+33,7 s^{2}+75,13 s+168,1}$ \\
Razão de refluxo & $G_{R}(s)=\frac{-0,0009891 s^{3}-0,007051 s^{2}-0,01278 s-0,05351}{s^{4}+9,497 s^{3}+47,06 s^{2}+116,4 s+278,5}$ \\
\hline
\end{tabular}

Fonte: Adaptado de Ketzer (2013).

Os modelos empíricos da Tabela 1 foram obtidos por Ketzer (2013) através da função System Identification do software Matlab, a qual permite a criação de modelos matemáticos a partir de dados experimentais de entradas e saídas do processo (relações de causalidade). Desse modo, os modelos acima relacionam o comportamento da temperatura do pré-condensador (sinal de saída) mediante a manipulação, nesta ordem, da vazão de vapor, vazão de água e razão de refluxo (sinais de entrada).

\subsection{Análise de estabilidade}

A análise da estabilidade compreendeu o estudo da dinâmica do sistema de controle em malha aberta, sem controlador, e em malha fechada, com controlador.

\subsubsection{Malha aberta}

A primeira análise consistiu em avaliar a estabilidade do sistema de controle em malha aberta para as três funções de transferência. Desse modo, foram avaliadas a estabilidade da malha de controle para $G_{V}(s), G_{A}(s)$ e $G_{R}(s)$ sem a presença do controlador. 
É sabido que a estabilidade de um sistema de controle em malha aberta é avaliada com base nos polos (raízes) do denominador da função de transferência do processo. Essa análise permite dizer se o sistema de controle em questão é estável ou não. Sendo assim, se o denominador de uma função de transferência apresentar pelo menos uma raiz com a parte real positiva, o sistema será instável

Dessa maneira, os denominadores das três funções de transferências foram igualados a zero, obtendo-se assim a equação característica para cada função de transferência em malha aberta. Posteriormente, os polos dessas equações foram obtidos com o auxílio do software Scilab por meio das funções poly (polinômio) e roots (raízes), as quais foram utilizadas para declarar as equações características no programa e obter as suas raízes.

\subsubsection{Malha fechada}

A segunda análise consistiu em avaliar a estabilidade do sistema de controle em malha fechada para as três funções de transferência na presença do controlador dotado apenas de ação proporcional. Dessa maneira, foram avaliadas a estabilidade da malha de controle para $G_{v}(s), G_{A}(s)$ e $\mathrm{G}_{\mathrm{R}}(\mathrm{s})$ com a presença do controlador.

Sabe-se que a estabilidade desse tipo de sistema de controle pode ser analisada com base no critério de estabilidade de Routh, o qual permite que o processo seja avaliado sem que seja necessário resolver a equação característica para a obtenção dos polos. O critério de estabilidade de Routh enuncia que todos os elementos da primeira coluna da Matriz de Routh sejam positivos para que o processo em questão seja estável. Os cálculos foram realizados com base no Quadro 1 mostrado anteriormente.

Dessa maneira, com o auxílio da função routh_t (diagrama de Routh) do Scilab foi possível investigar se o sistema de controle em malha fechada para as três funções de transferência era estável ou não.

\subsection{Sintonia de controladores}

A sintonia dos controladores P, PI e PID foi realizada com base no método de Ziegler e Nichols, o qual baseia-se em encontrar o limite de estabilidade da malha de controle. O ganho último $\left(\mathrm{K}_{\mathrm{U}}\right)$ e o período último de oscilação $\left(\mathrm{P}_{\mathrm{U}}\right)$ necessários para a utilização desse método foram obtidos, nesta ordem, por meio do método de Routh e da substituição direta, considerando apenas as funções de transferência do processo e do controlador proporcional.

De posse dos valores do ganho último $\left(\mathrm{K}_{\mathrm{U}}\right)$ e do período último de oscilação $\left(\mathrm{P}_{\mathrm{U}}\right)$, usaramse as correlações de Ziegler e Nichols (STEPHANOPOULOS, 1984; LUYBEN, 1990; NUNES, MEDEIROS E ARAÚJO, 2010) para determinar os parâmetros dos três controladores avaliados, a saber o ganho proporcional $\left(\mathrm{K}_{\mathrm{P}}\right)$, a constante de tempo integral $\left(\tau_{\mathrm{I}}\right)$ e a constante de tempo 
derivativa $\left(\tau_{D}\right)$. Por fim, esses parâmetros foram utilizados para ajustar os controladores P, PI e PID e serviram de base para a escolha da melhor estratégia de controle.

A escolha da melhor estratégia de controle se deu por meio da observação gráfica do sinal de saída do processo, isto é, do comportamento da temperatura do pré-condensador em função do tempo, para os três tipos de controladores. Desse modo, o melhor controlador foi aquele capaz de estabilizar o processo num menor intervalo de tempo e com menor variação de resposta.

\section{Resultados e discussões}

\subsection{Análise de estabilidade}

\subsubsection{Malha aberta}

A estabilidade do sistema de controle em malha aberta foi analisada a partir dos polos, ou seja, das raízes do denominador da função de transferência do processo. A obtenção dos polos se deu no software Scilab por meio das funções poly (polinômio) e roots (raízes), as quais foram utilizadas para declarar o denominador da função de transferência do processo e obter as suas raízes. São mostrados na Tabela 2 os polos das funções $G_{V}(s), G_{A}(s)$ e $G_{R}(s)$ elaboradas para a coluna de destilação descontínua estudada.

Tabela 2: Polos das funções de transferências avaliadas.

\begin{tabular}{|c|c|c|}
\hline & Função de transferência & Polos (raízes) \\
\hline & $0,0004657 \mathrm{~s}+1,361 \times 10^{-7}$ & $-0,3096$ \\
\hline & $s^{2}+0,3096 s+8,013 \times 10^{-10}$ & $-2,5880 \times 10^{-9}$ \\
\hline & $-1,266 s^{3}-9,229 s^{2}-20,4 s-74,26$ & $-2,5192 \pm 3,1419 i$ \\
\hline & $G_{A}(s)=\overline{s^{4}+6,451 s^{3}+33,7 s^{2}+75,13 s+168,1}$ & $-0,7062 \pm 3,1409 i$ \\
\hline \multirow{2}{*}{$\mathbf{G}_{\mathbf{R}}(\mathbf{s})$} & $-0,0009891 s^{3}-0,007051 s^{2}-0,01278 s-0,05351$ & $-4,1769 \pm 3,1412 i$ \\
\hline & $s^{4}+9,497 s^{3}+47,06 s^{2}+116,4 s+278,5$ & $-0,5715 \pm 3,1415 i$ \\
\hline
\end{tabular}

A partir da análise da Tabela 2, observa-se que as raízes obtidas pelo software Scilab para os denominadores das funções $G_{V}(s), G_{A}(s)$ e $G_{R}(s)$ possuem a parte real negativa, logo apresentam um comportamento estável. Esse comportamento estável também foi observado graficamente através da plataforma Xcos do programa Scilab, o qual permite que seja elaborado o diagrama de blocos do sistema de controle em questão.

A Figura 2 ilustra o diagrama de blocos do sistema de controle em malha aberta para a função de transferência $G_{v}(s)$ obtida por meio da manipulação da vazão de vapor do destilador ou refervedor.

Observa-se, da esquerda para a direita, o bloco referente ao degrau e o bloco referente ao processo, cuja função de transferência $\mathrm{G}_{\mathrm{V}}(\mathrm{s})$ é mostrada em seu interior. O bloco, cujo valor 351,5993 é mostrado em seu interior, ligado ao bloco $\sum$, foi utilizado para obter a temperatura final do pré-condensador e não o desvio dessa temperatura em relação ao setpoint (351,5993 K). Já outro 
ISSN: $1415-7314$

ISSN online: $2317-6717$

bloco de valor 351,5993, conectado ao bloco MUX, foi usado para inserir a linha do setpoint nos gráficos gerados. Os demais blocos são apenas blocos comuns ao funcionamento da malha de controle.

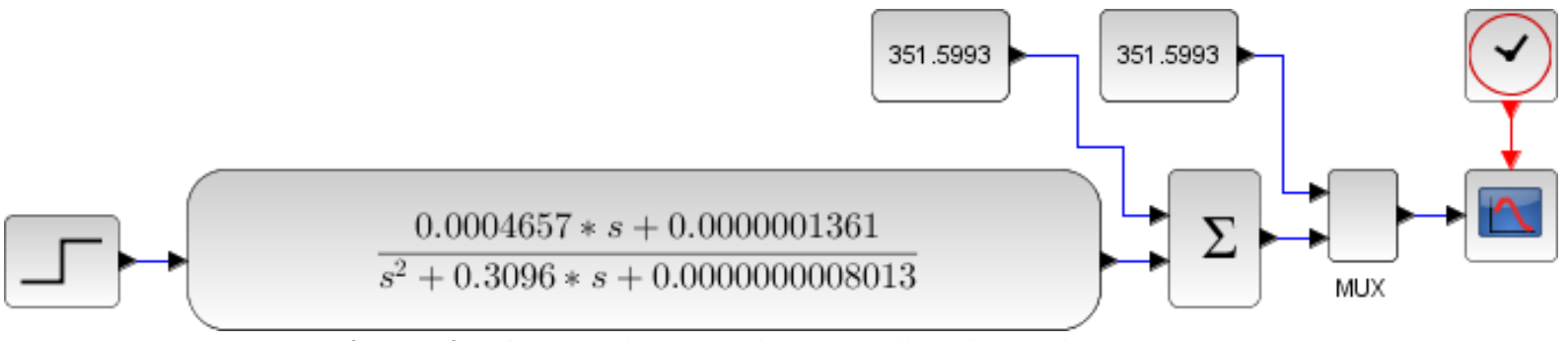

Figura 2: Sistema de controle em malha aberta de $\mathrm{G}_{\mathrm{V}}(\mathrm{s})$.

Fonte: Resultados da pesquisa.

Por meio do diagrama de blocos da Figura 2, foi possível obter o comportamento gráfico do sinal de saída (temperatura do pré-condensador) desse sistema de controle em malha aberta diante de uma perturbação degrau em seu sinal de entrada (vazão de vapor). A perturbação degrau ou step é caracterizada por uma mudança abrupta no valor da variável manipulada, a qual pode assumir diversos valores.

Dessa maneira, obteve-se graficamente o comportamento da temperatura $(\mathrm{K})$ do précondensador em função do tempo (s) após o processo sofrer uma mudança brusca na vazão de vapor que adentra o destilador de $0,0333 \mathrm{~m}^{3} / \mathrm{s}$ para $0,1667 \mathrm{~m}^{3} / \mathrm{s}$. A Figura 3 ilustra o comportamento da temperatura do pré-condensador após o sistema de controle em malha aberta sofrer uma perturbação degrau igual a $0,1334 \mathrm{~m}^{3} / \mathrm{s}\left(0,1667 \mathrm{~m}^{3} / \mathrm{s}-0,0333 \mathrm{~m}^{3} / \mathrm{s}\right)$.

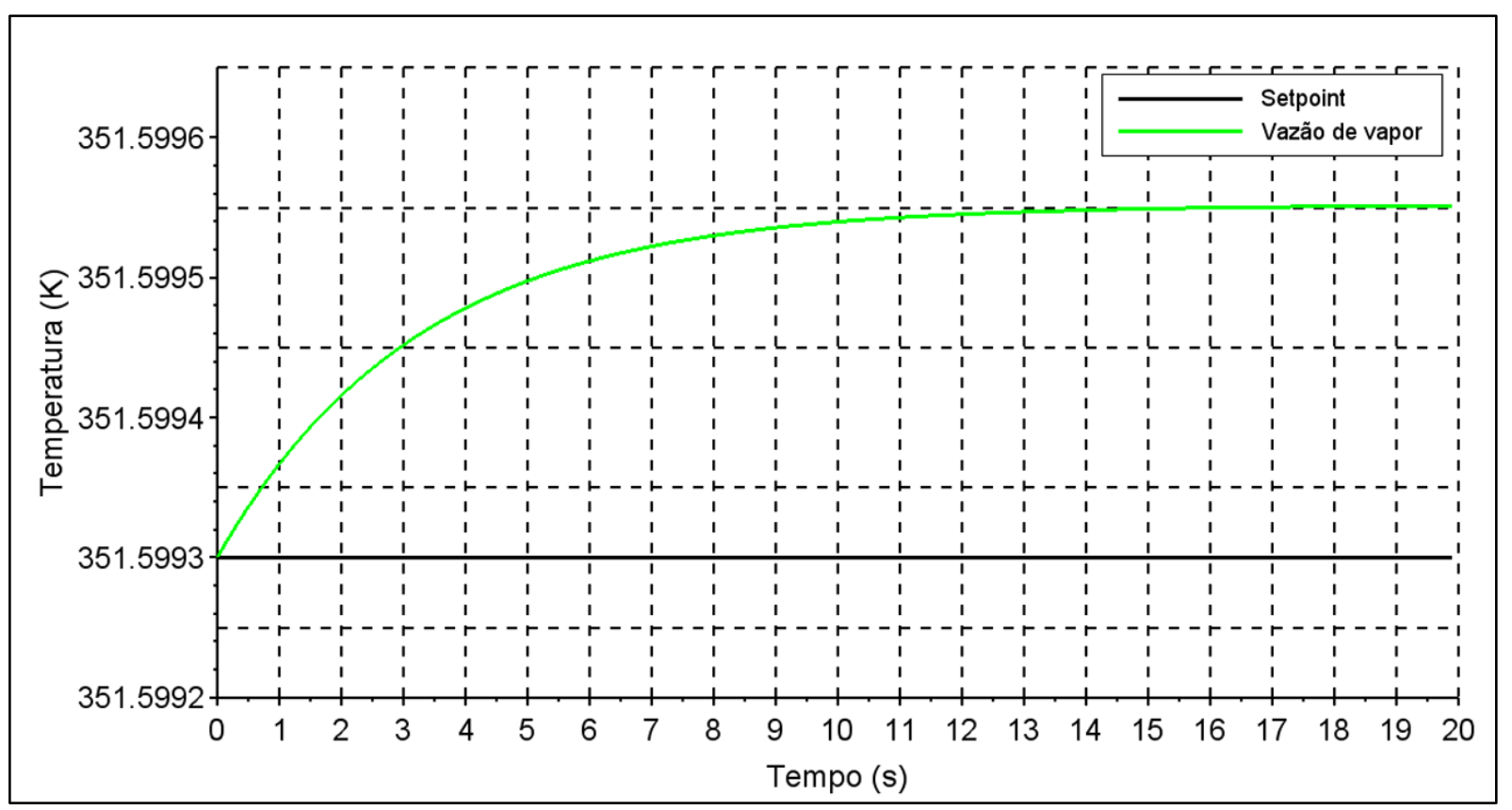

Figura 3: Temperatura do pré-condensador para $\mathrm{G}_{\mathrm{V}}(\mathrm{s})$.

Fonte: Resultados da pesquisa.

A primeira análise que pode ser feita por meio da Figura 3 é a de que esse sistema de controle em malha aberta apresenta um comportamento estável. De acordo com a Figura 3, esse 
comportamento é alcançado após $15 \mathrm{~s}$ com um desvio aproximado de $0,0002 \mathrm{~K}$ da temperatura desejada para o pré-condensador de 351,5993 K.

Sabe-se que o desvio é a diferença entre o valor medido para a temperatura do précondensador e o valor desejado (setpoint) para ela. Portanto, para o setpoint de 351,5993 K, o valor alcançado para a temperatura do pré-condensador por esse sistema de controle em malha aberta, considerando o desvio de $0,0002 \mathrm{~K}$, será de aproximadamente $351,5995 \mathrm{~K}$, a qual pode ser observada para tempos superiores a $15 \mathrm{~s}$ na Figura 3.

Apesar de o sistema de controle em malha aberta alcançar uma certa estabilidade após sofrer uma perturbação degrau de $0,1334 \mathrm{~m}^{3} / \mathrm{s}$, é importante destacar que esta não é, necessariamente, a condição de temperatura que se deseja para o pré-condensador. Logo, faz-se necessário o uso de um controlador para que o valor da temperatura do pré-condensador seja igual ao valor desejado para ela ou próxima dela (351,5993 K).

A Figura 4 ilustra o diagrama de blocos do sistema de controle em malha aberta para $\mathrm{G}_{\mathrm{A}}(\mathrm{s})$ obtida através da manipulação da vazão de água do pré-condensador. Igualmente, é possível observar, da esquerda para a direita, os blocos referentes ao degrau, ao processo e ao funcionamento da malha de controle como dito para $\mathrm{G}_{\mathrm{v}}(\mathrm{s})$.

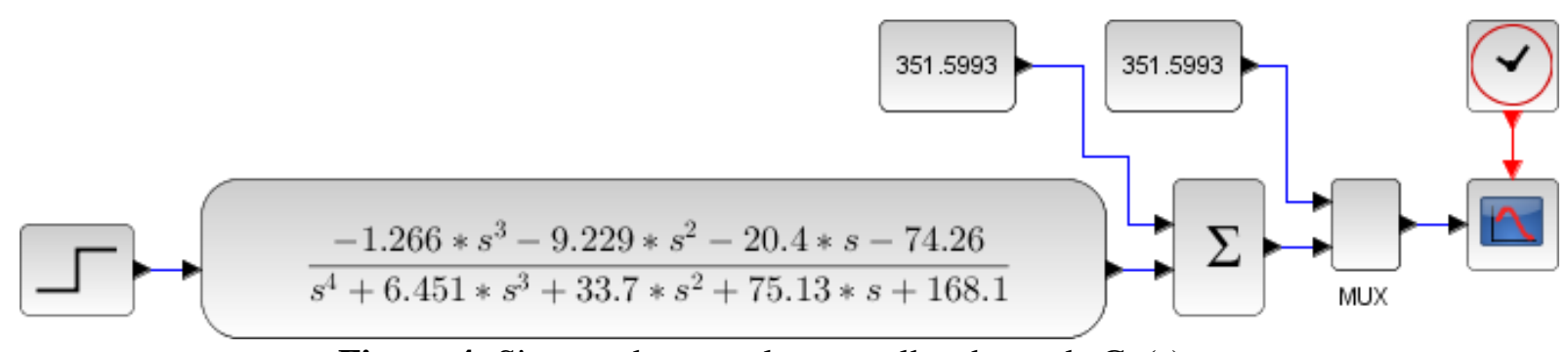

Figura 4: Sistema de controle em malha aberta de $\mathrm{G}_{\mathrm{A}}(\mathrm{s})$.

Fonte: Resultados da pesquisa.

Semelhantemente, por meio do diagrama de blocos da Figura 4, obteve-se o comportamento gráfico da temperatura $(\mathrm{K})$ do pré-condensador em função do tempo (s) após uma perturbação degrau na vazão de água que adentra o pré-condensador de $0,0002 \mathrm{~m}^{3} / \mathrm{s}$ para 0,0008 $\mathrm{m}^{3} / \mathrm{s}$, caracterizando um degrau de $0,0006 \mathrm{~m}^{3} / \mathrm{s}$ na vazão de água (Figura 5). 


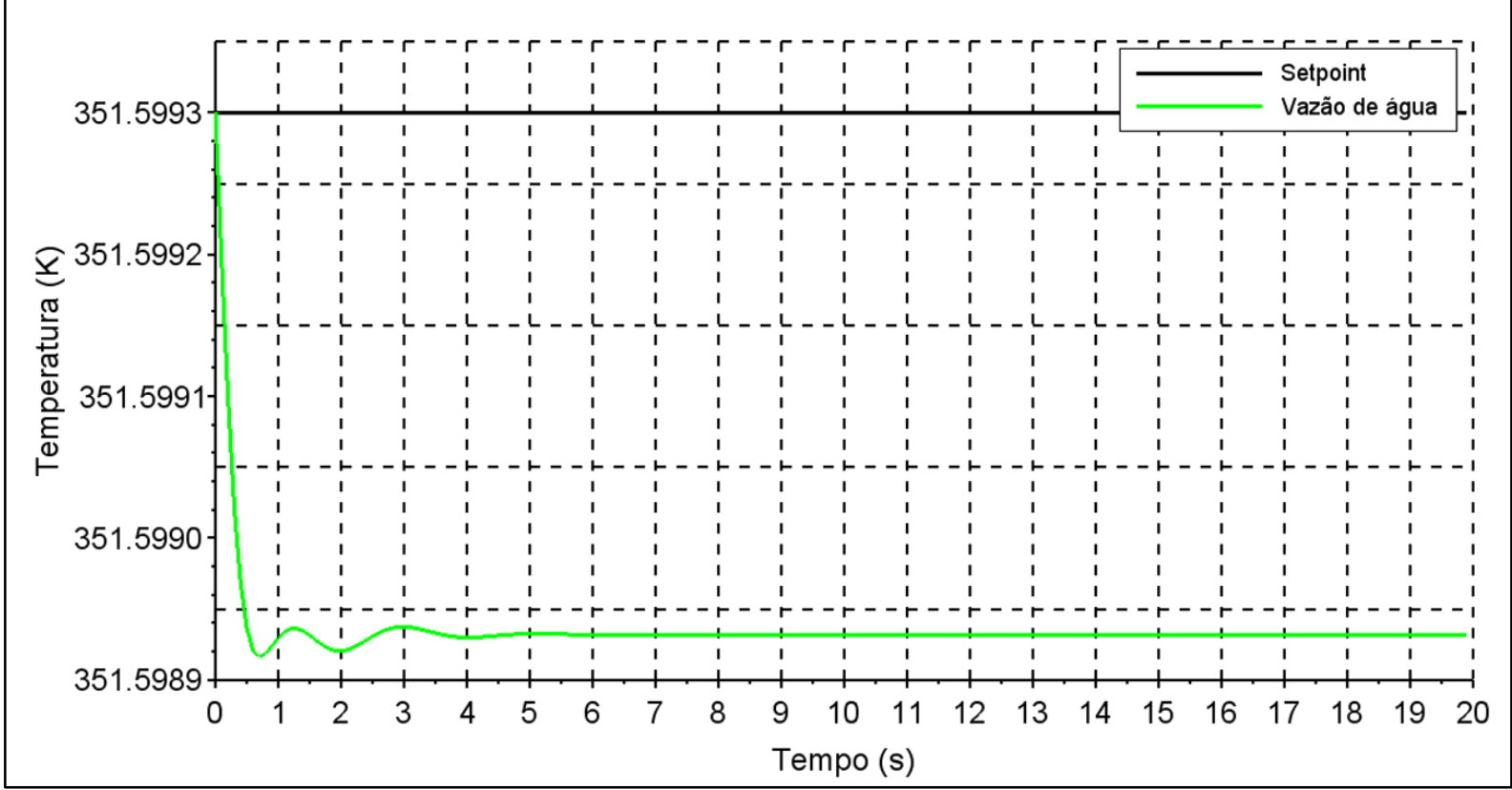

Figura 5: Temperatura do pré-condensador para $\mathrm{G}_{\mathrm{A}}(\mathrm{s})$.

Fonte: Resultados da pesquisa.

A partir da Figura 5, foi possível observar que esse sistema de controle em malha aberta apresenta um comportamento estável, o qual é atingido após $5 \mathrm{~s}$ com um desvio aproximado de 0,0004 K. Desse modo, para o setpoint de 351,5993 K, o valor alcançado para a temperatura do pré-condensador por esse sistema de controle em malha aberta será de aproximadamente 351,5989 $\mathrm{K}$.

A Figura 6 ilustra o diagrama de blocos do sistema de controle em malha aberta para a função de transferência $G_{R}(s)$ obtida por meio da manipulação da razão de refluxo, ou seja, por meio da manipulação da vazão de produto destilado que retorna para a coluna de destilação. Igualmente, é possível observar os blocos referentes ao degrau, ao processo e ao funcionamento da malha de controle como dito para $\mathrm{G}_{\mathrm{V}}(\mathrm{s})$.

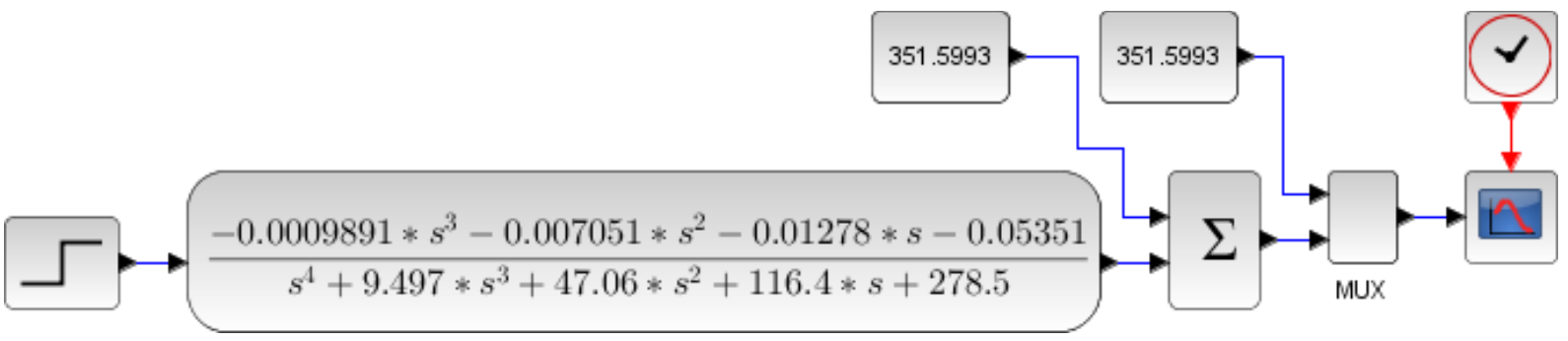

Figura 6: Sistema de controle em malha aberta de $\mathrm{G}_{\mathrm{R}}(\mathrm{s})$.

Fonte: Resultados da pesquisa.

Por meio do diagrama de blocos da Figura 6, foi possível obter o comportamento gráfico da temperatura (K) do pré-condensador em função do tempo (s) após o processo sofrer uma perturbação degrau na razão de refluxo de 2 para 10, caracterizando um degrau igual a 8 (Figura 7). É importante lembrar que a razão de refluxo é um quociente entre a vazão de reciclo e a vazão de produto destilado. Dessa maneira, não possui unidade. 


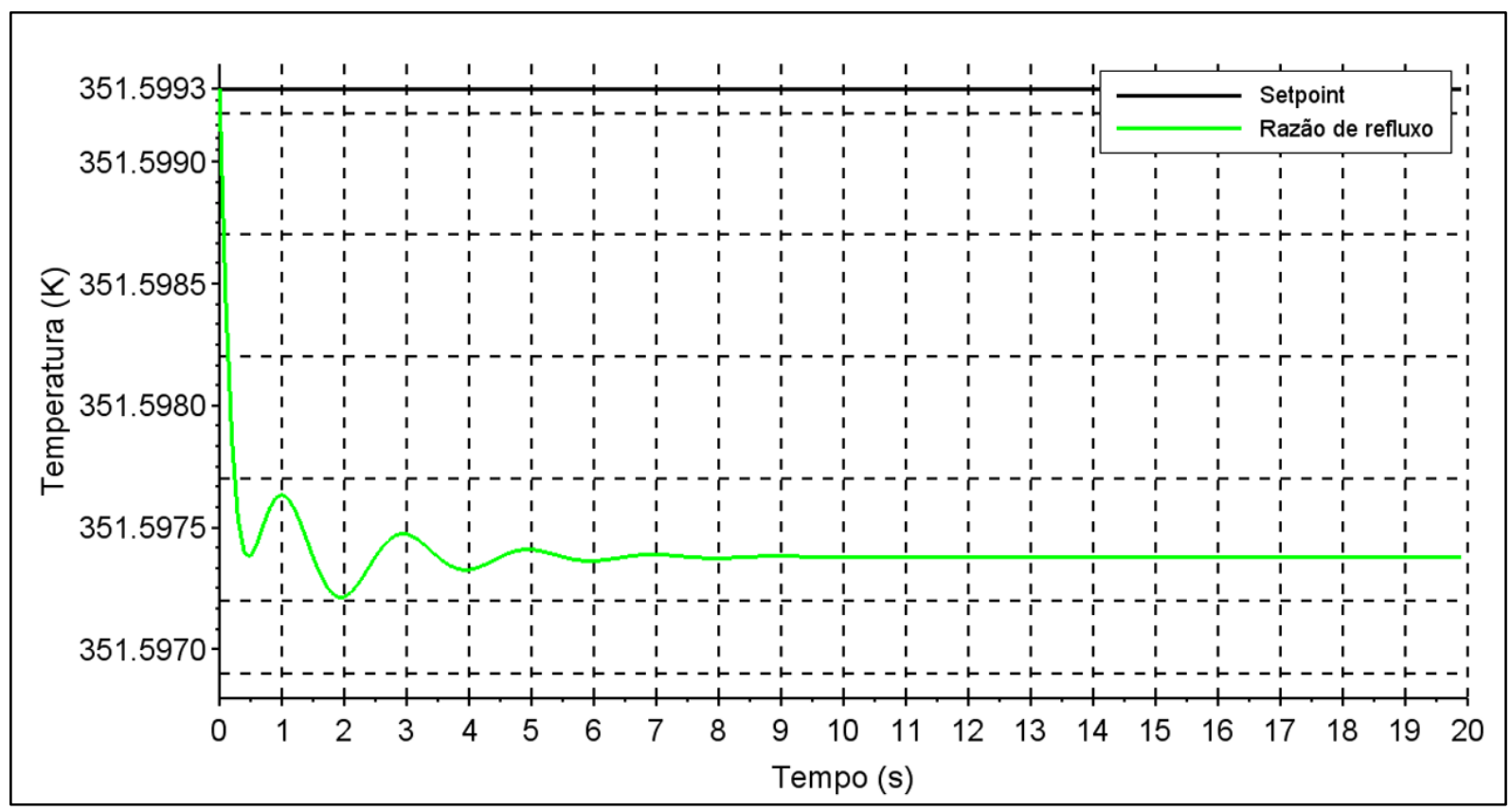

Figura 7: Temperatura do pré-condensador para $\mathrm{G}_{\mathrm{R}}(\mathrm{s})$.

Fonte: Resultados da pesquisa.

A primeira análise que pode ser feita a partir da Figura 7 é a de que esse sistema de controle em malha aberta possui um comportamento estável, o qual é alcançado após $8 \mathrm{~s}$ com um desvio aproximado de 0,002 K. Desse modo, para o setpoint de 351,5993 K, o valor alcançado para a temperatura do pré-condensador por esse sistema de controle em malha aberta será de aproximadamente $351,5973 \mathrm{~K}$.

Embora os desvios encontrados sejam baixos $\left(0,0002 \mathrm{~K}\right.$ para $\mathrm{G}_{\mathrm{V}}(\mathrm{s}), 0,0004 \mathrm{~K}$ para $\mathrm{G}_{\mathrm{A}}(\mathrm{s})$ e $0,002 \mathrm{~K}$ para $\mathrm{G}_{\mathrm{R}}(\mathrm{s})$ ), eles demonstram que os sistemas de controle em malha aberta para essas funções de transferência necessitam de um controlador para que a variável de interesse (temperatura do pré-condensador) seja igual ao valor desejado para ela de 351,5993 K.

\subsubsection{Malha fechada}

A estabilidade do sistema de controle em malha fechada foi analisada a partir do critério de estabilidade de Routh. Dessa maneira, a análise dos polos da equação característica se deu no software Scilab por meio da função routh_t (diagrama de Routh), a qual foi utilizada para gerar a matriz de Routh sem que fosse necessário calcular os polos daquela equação.

\subsection{Sintonia de controladores}

Os valores do ganho último $\left(\mathrm{K}_{\mathrm{U}}\right)$ e do período último $\left(\mathrm{P}_{\mathrm{U}}\right)$, utilizados no método de Ziegler e Nichols, foram encontrados através da matriz de Routh para $G_{V}(s), G_{A}(s)$ e $G_{R}(s)$ com o auxílio do Scilab. Para isso, utilizaram-se as funções poly (polinômio) e roots (raízes), as quais foram usadas, respectivamente, para declarar as equações no programa e obter as suas raízes. Com os 
valores de $K_{U}$ e $P_{U}$ de $G_{V}(s), G_{A}(s)$ e $G_{R}(s)$, foi possível obter os parâmetros dos controladores P, PI e PID através das correlações propostas por Ziegler e Nichols.

\subsubsection{Vazão de vapor}

Por meio do software Scilab, foi possível obter todos os valores de K da primeira coluna da matriz de Routh para o sistema de controle em malha fechada para a variável manipulada vazão de vapor. Dentre eles, escolheu-se o valor de K que satisfaz o critério de estabilidade de Routh, isto é, que faz com que todos os elementos da primeira coluna da matriz de Routh sejam positivos e, consequentemente, o processo seja estável. Esse valor é chamado de ganho último $\left(\mathrm{K}_{\mathrm{U}}\right)$ e é mostrado na Tabela 3.

Tabela 3: Ganho último para a função de transferência $\mathrm{G}_{\mathrm{V}}(\mathrm{s})$.

\begin{tabular}{cc}
\hline Função de transferência & Ganho último $\left(\mathrm{K}_{\mathrm{U}}\right)$ \\
\hline $\mathrm{G}_{\mathrm{V}}(\mathrm{s})=\frac{0,0004657 \mathrm{~s}+1,361 \times 10^{-7}}{\mathrm{~s}^{2}+0,3096 \mathrm{~s}+8,013 \times 10^{-10}}$ & 664,8056 \\
\hline
\end{tabular}

De posse do valor de $\mathrm{K}_{\mathrm{U}}$, foi possível calcular o valor do período último de oscilação $\left(\mathrm{P}_{\mathrm{U}}\right)$ correspondente. Para isso, considerou-se a equação característica elementar de um sistema de controle em malha fechada: $1+\mathrm{G}_{\mathrm{P}}(\mathrm{s}) \mathrm{G}_{\mathrm{C}}(\mathrm{s})=0$, onde $\mathrm{G}_{\mathrm{P}}(\mathrm{s})=\mathrm{G}_{\mathrm{V}}(\mathrm{s})$ e $\mathrm{G}_{\mathrm{C}}(\mathrm{s})=\mathrm{K}_{\mathrm{U}}$ (função de transferência do controlador P).

Após manipulações matemáticas, obteve-se a seguinte equação no domínio s e em função de $\mathrm{K}_{\mathrm{U}}$ :

$$
\mathrm{s}^{2}+0,3096 \mathrm{~s}+8,013 \times 10^{-10}+\left(0,0004657 \mathrm{~s}+1,361 \times 10^{-7}\right) \mathrm{K}_{\mathrm{u}}=0
$$

A solução desse tipo de equação, em alguns casos, exige o uso de técnicas matemáticas que sejam capazes de simplificar o seu grau de complexidade, por exemplo, o método da substituição direta, o qual consiste em substituir $s$ por $\omega i$ na equação característica acima. Dessa maneira, substituindo $s$ por $\omega i$ e considerando que $i^{2}=-1$ obtém-se:

$$
-\omega^{2}+0,3096 \omega \mathrm{i}+8,013 \times 10^{-10}+0,0004657 \omega i K_{u}+1,361 \times 10^{-7} K_{u}=0
$$

Para que a equação característica complexa acima seja igual a zero, é necessário que a sua parte real e imaginária sejam também iguais a zero. Portanto:

Parte real:

$$
\left(-\omega^{2}+8,013 \times 10^{-10}+1,361 \times 10^{-7} K_{u}\right)=0
$$

Parte imaginária:

$$
\left(0,3096 \omega+0,0004657 \omega K_{u}\right) i=0
$$

Considerando que $\mathrm{K}_{\mathrm{U}}$ é igual a 664,8056 e que $\omega$ é a frequência angular, a qual é calculada através da equação $\omega=2 \pi / \mathrm{P}_{\mathrm{U}}$, obtém-se a Tabela 4 com os valores do ganho último $\left(\mathrm{K}_{\mathrm{U}}\right)$ e do 
período último $\left(\mathrm{P}_{\mathrm{U}}\right)$ para o sistema de controle em malha fechada para a variável manipulada vazão de vapor.

Tabela 4: Valores de $K_{U}$ e $P_{U}$ para a função de transferência $G_{V}(s)$.

$\begin{array}{cc}\text { Ganho último }\left(\mathrm{K}_{\mathrm{U}}\right) & \text { Período último }\left(\mathrm{P}_{\mathrm{U}}\right) \\ \mathbf{6 6 4 , 8 0 5 6} & 661,3879\end{array}$

A partir dos valores de $\mathrm{K}_{\mathrm{U}}$ e de $\mathrm{P}_{\mathrm{U}}$, obtiveram-se os parâmetros dos controladores P, PI e PID ( $\mathrm{K}_{\mathrm{P}}$, $\tau_{I}$ e $\tau_{D}$ ) por meio das correlações de Ziegler e Nichols, os quais são mostrados na Tabela 5.

Tabela 5: Parâmetros dos controladores para a função de transferência $\mathrm{G}_{\mathrm{V}}(\mathrm{s})$.

\begin{tabular}{cccc}
\hline Controlador & $\mathrm{K}_{\mathrm{P}}$ & $\tau_{\mathrm{I}}$ & $\tau_{\mathrm{D}}$ \\
\hline $\mathbf{P}$ & 332,4028 & - & - \\
PI & 302,1843 & 550,4554 & - \\
PID & 391,0621 & 330,2732 & 82,5683 \\
\hline
\end{tabular}

De posse dos valores de $K_{P}, \tau_{I}$ e $\tau_{D}$ da Tabela 5, foi possível obter o comportamento gráfico da temperatura $(\mathrm{K})$ do pré-condensador em função do tempo (s) para a variável manipulada vazão de vapor. Tal comportamento foi conseguido para o sistema de controle em malha fechada dotado dos controladores P e PI (Figura 8) e PID (Figura 9).

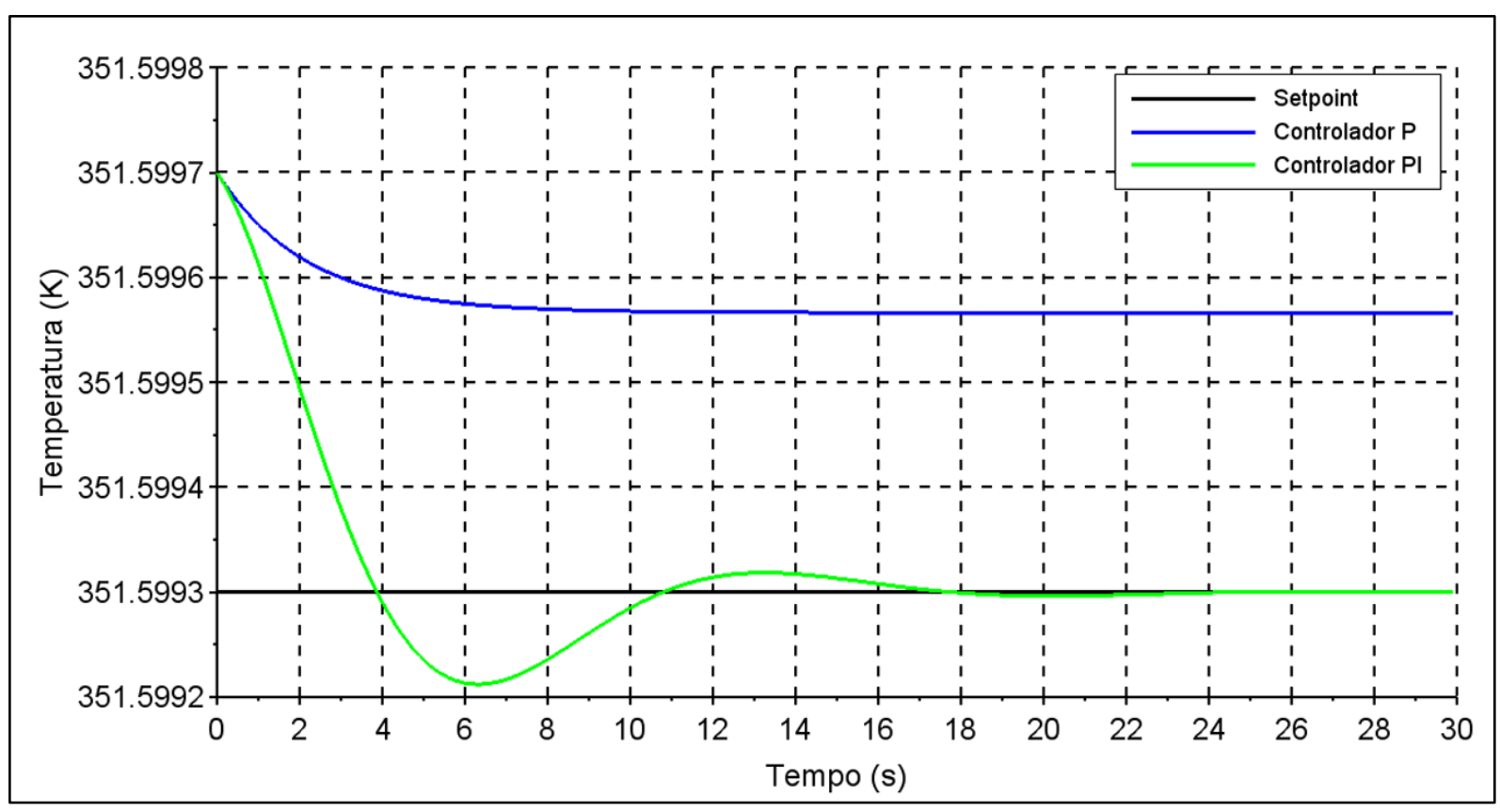

Figura 8: Saída do sistema de controle de $\mathrm{G}_{\mathrm{V}}(\mathrm{s})$ para os controladores $\mathrm{P}$ e PI. Fonte: Resultados da pesquisa. 


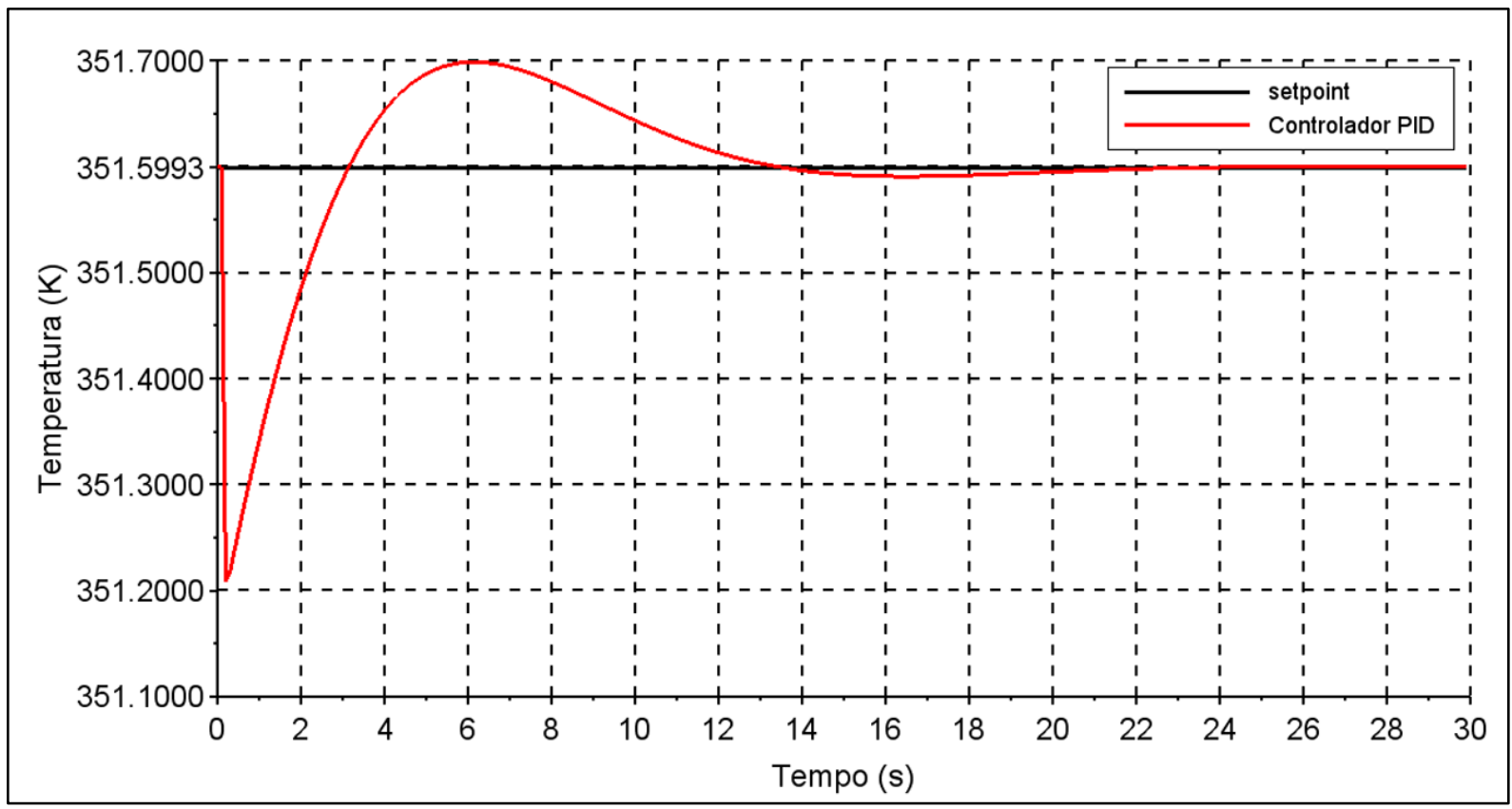

Figura 9: Saída do sistema de controle de $\mathrm{G}_{\mathrm{V}}(\mathrm{s})$ para o controlador PID. Fonte: Resultados da pesquisa.

A partir da Figura 8 e Figura 9, foi possível observar que o sistema de controle em malha fechada para a variável vazão de vapor alcançou uma certa estabilidade com o passar do tempo para os controladores P, PI e PID, embora esse tempo seja diferente para cada um deles, respectivamente, $16 \mathrm{~s}, 24 \mathrm{~s}$ e $22 \mathrm{~s}$.

Apesar de o controlador P alcançar um comportamento estável, é importante lembrar que este comportamento não é o que se deseja para a temperatura do pré-condensador. Segundo a Figura 8, o controlador P estabiliza a temperatura do pré-condensador entre 351,5995 K e 351, 5996 K. Uma vez que o setpoint é 351,5993 K, esta temperatura está acima do valor desejado. Esse desvio, conhecido na prática como offset, entre o setpoint e o valor medido já era esperado, pois é característico desse tipo de controlador.

Segundo a Figura 9, os controladores P e PI foram capazes de manter a temperatura do précondensador no valor desejado para ela de 351,5993 K. Dentre eles, o que melhor desempenhou a sua função foi o controlador PI, embora o controlador PID tenha sido capaz de estabilizar o processo em um menor intervalo de tempo. A escolha do controlador PI se deu em consequência dele ter estabilizado a temperatura do pré-condensador com uma pequena variação, a qual foi maior para o PID.

\subsubsection{Vazão de água}

De maneira análoga ao que foi feito para $\mathrm{G}_{\mathrm{V}}(\mathrm{s})$, foi possível obter todos os valores de $\mathrm{K}$ da primeira coluna da matriz de Routh para o sistema de controle em malha fechada para a variável manipulada vazão de água. Dentre eles, escolheu-se o valor de K que satisfaz o critério de estabilidade de Routh. Esse valor é chamado de ganho último $\left(\mathrm{K}_{\mathrm{U}}\right)$ e é mostrado na Tabela 6 . 
Tabela 6: Ganho último para a função de transferência $\mathrm{G}_{\mathrm{A}}(\mathrm{s})$.

\begin{tabular}{cc}
\hline Função de transferência & Ganho último $\left(\mathrm{K}_{\mathrm{U}}\right)$ \\
\hline $\mathrm{G}_{\mathrm{A}}(\mathrm{s})=\frac{-1,266 \mathrm{~s}^{3}-9,229 \mathrm{~s}^{2}-20,4 \mathrm{~s}-74,26}{\mathrm{~s}^{4}+6,451 \mathrm{~s}^{3}+33,7 \mathrm{~s}^{2}+75,13 \mathrm{~s}+168,1}$ & 2,2636 \\
\hline
\end{tabular}

De posse do valor de $\mathrm{K}_{\mathrm{U}}$, calculou-se o valor do período último $\left(\mathrm{P}_{\mathrm{U}}\right)$ correspondente. Para isso, considerou-se a equação característica elementar de um sistema de controle em malha fechada: $1+\mathrm{G}_{\mathrm{P}}(\mathrm{s}) \mathrm{G}_{\mathrm{C}}(\mathrm{s})=0$, onde $\mathrm{G}_{\mathrm{P}}(\mathrm{s})=\mathrm{G}_{\mathrm{V}}(\mathrm{s})$ e $\mathrm{G}_{\mathrm{C}}(\mathrm{s})=\mathrm{K}_{\mathrm{U}}$. Do mesmo modo, após manipulações matemáticas, obteve-se a seguinte equação no domínio s e em função de $\mathrm{K}_{\mathrm{U}}$ :

$$
s^{4}+6,451 s^{3}+33,7 s^{2}+75,13 s+168,1+\left(-1,266 s^{3}-9,229 s^{2}-20,4 s-74,26\right) k_{u}=0
$$

Da mesma maneira, utilizou-se o método da substituição direta para simplificar o grau de complexidade da equação acima, o qual consiste em substituir $s$ por $\omega i$ na equação característica. Logo, substituindo $s$ por $\omega i$ e considerando que $i^{2}=-1$ obtém-se:

$$
\begin{gathered}
\omega^{4}-6,451 \omega^{3} \mathrm{i}-33,7 \omega^{2}+75,13 \omega \mathrm{i}+168,1+\left(1,266 \omega^{3} \mathrm{i}+9,229 \omega^{2}-20,4 \omega \mathrm{i}-74,26\right) \mathrm{k}_{\mathrm{u}} \\
=0
\end{gathered}
$$

Para que a equação característica complexa acima seja igual a zero, é necessário que a sua parte real e imaginária sejam também iguais a zero. Portanto:

Parte real:

$$
\left(\omega^{4}-33,7 \omega^{2}+168,1+9,229 \omega^{2} k_{u}-74,26 k_{u}\right)=0
$$

Parte imaginária:

$$
\left(-6,451 \omega^{3}+75,13 \omega+1,266 \omega^{3} k_{u}-20,4 \omega k_{u}\right) i=0
$$

Considerando que $\mathrm{K}_{\mathrm{U}}$ é igual a 2,2636 e que $\omega$ é a frequência angular, a qual é calculada através da equação $\omega=2 \pi / \mathrm{P}_{\mathrm{U}}$, obtém-se a Tabela 7 com os valores do ganho último $\left(\mathrm{K}_{\mathrm{U}}\right)$ e do período último de oscilação $\left(\mathrm{P}_{\mathrm{U}}\right)$ para o sistema de controle em malha fechada para a variável manipulada vazão de água.

Tabela 7: Valores de $\mathrm{K}_{U}$ e $\mathrm{P}_{\mathrm{U}}$ para a função de transferência $\mathrm{G}_{\mathrm{A}}(\mathrm{s})$.

\begin{tabular}{cc}
\hline Ganho último $\left(\mathrm{K}_{\mathrm{U}}\right)$ & Período último $\left(\mathrm{P}_{\mathrm{U}}\right)$ \\
\hline $\mathbf{2 , 2 6 3 6}$ & $-1,7556$ \\
\hline
\end{tabular}

Da mesma maneira, a partir dos valores do ganho último $\left(\mathrm{K}_{\mathrm{U}}\right)$ e do período último $\left(\mathrm{P}_{\mathrm{U}}\right)$ obtiveram-se os parâmetros dos controladores P, PI e PID $\left(K_{P}, \tau_{I}\right.$ e $\left.\tau_{D}\right)$ por meio das correlações de Ziegler e Nichols, os quais são mostrados na Tabela 8. 
Tabela 8: Parâmetros dos controladores para a função de transferência $\mathrm{G}_{\mathrm{A}}(\mathrm{s})$.

\begin{tabular}{cccc}
\hline Controlador & $\mathrm{K}_{\mathrm{P}}$ & $\tau_{\mathrm{I}}$ & $\tau_{\mathrm{D}}$ \\
\hline $\mathbf{P}$ & 1,1318 & - & - \\
$\mathbf{P I}$ & 1,0289 & $-1,4630$ & - \\
PID & 1,3315 & $-0,8778$ & $-0,2194$ \\
\hline
\end{tabular}

Com os valores de $K_{P}$, $\tau_{I}$ e $\tau_{D}$ da Tabela 8 , foi possível obter o comportamento gráfico da temperatura $(\mathrm{K})$ do pré-condensador em função do tempo (s) para a variável manipulada vazão de água. Tal comportamento foi conseguido para o sistema de controle em malha fechada dotado dos controladores P e PI (Figura 10) e PID (Figura 11).

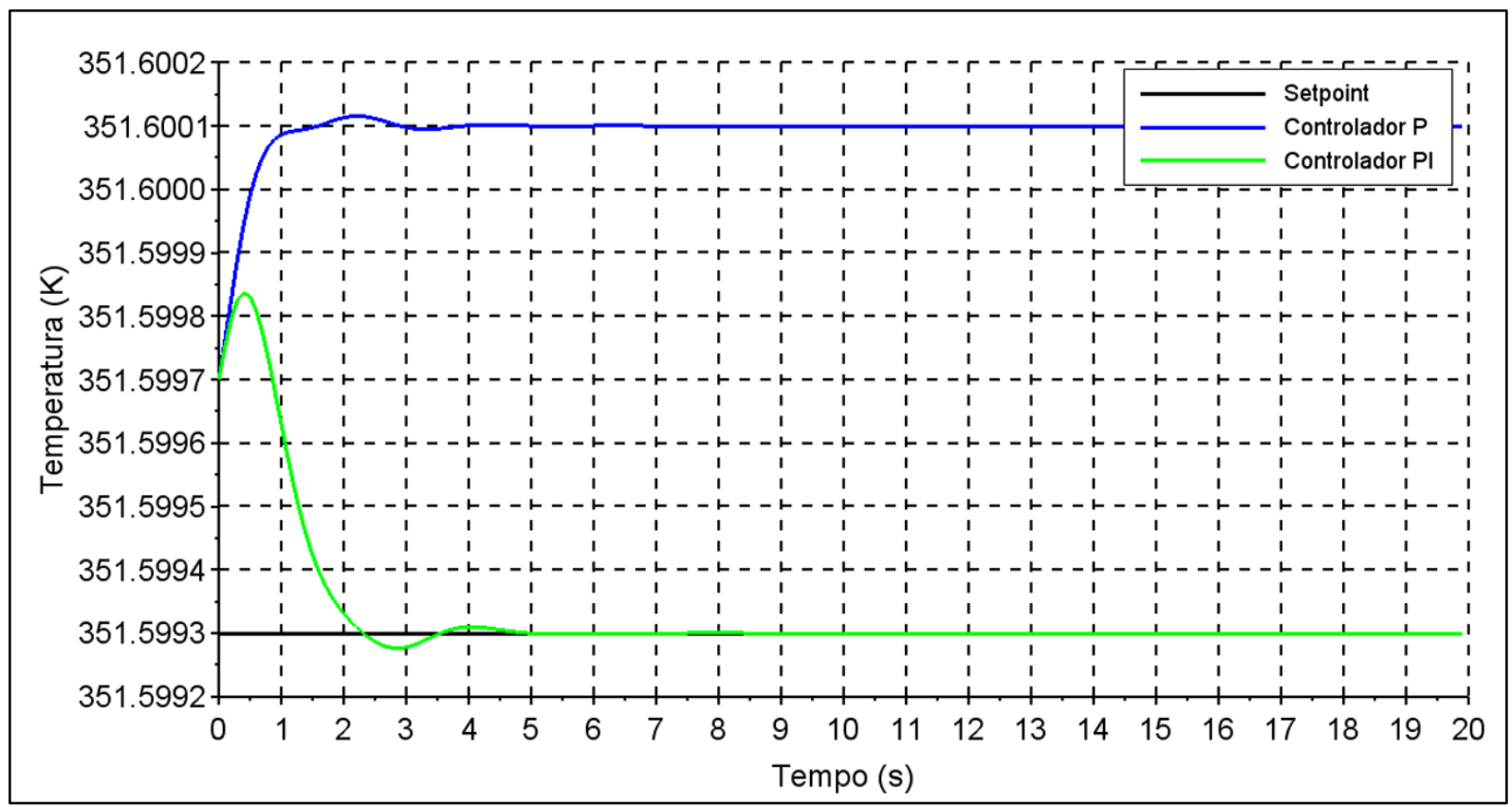

Figura 10: Saída do sistema de controle de $\mathrm{G}_{\mathrm{A}}(\mathrm{s})$ para os controladores $\mathrm{P}$ e PI. Fonte: Resultados da pesquisa.

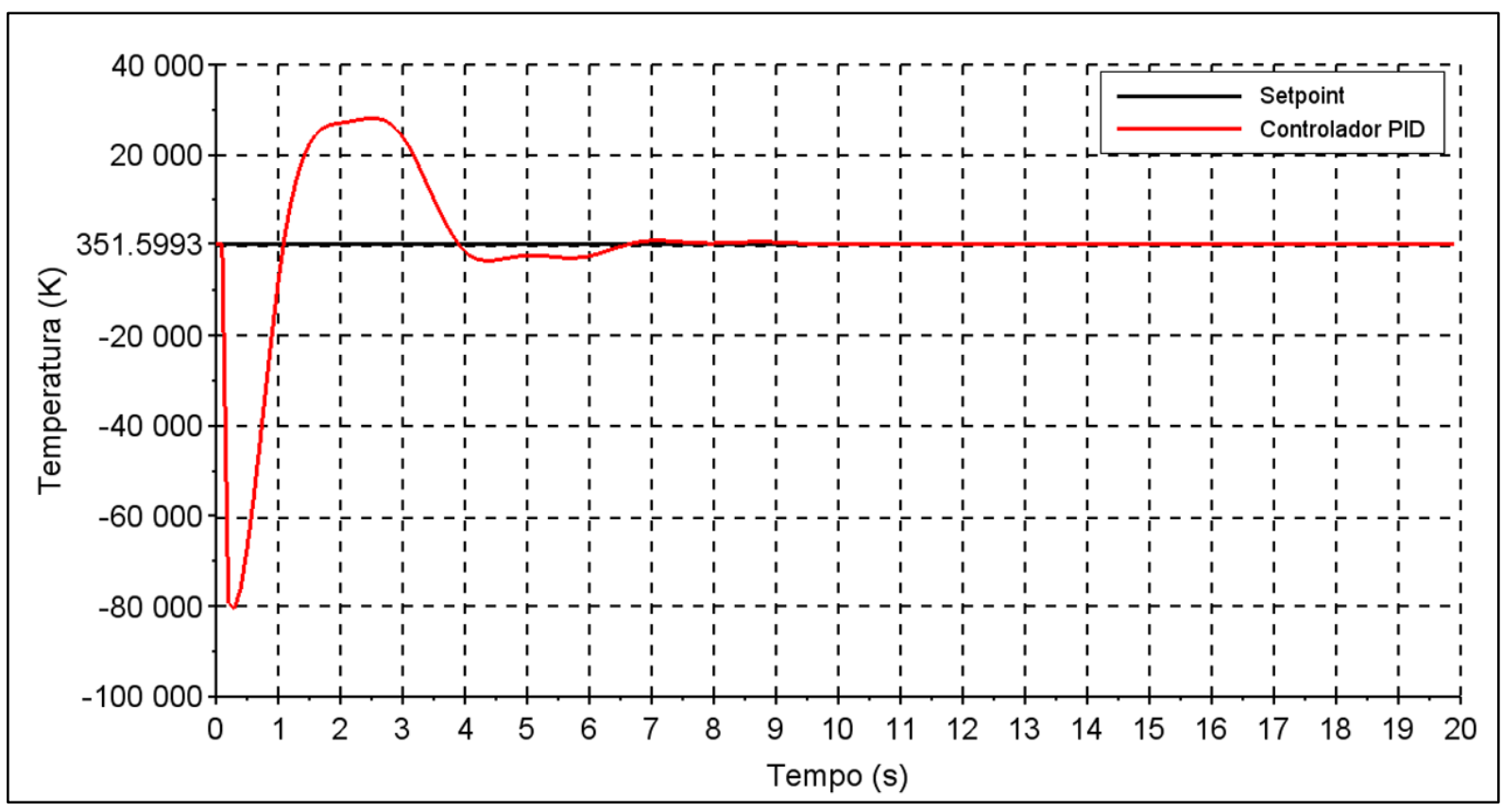

Figura 11: Saída do sistema de controle de $\mathrm{G}_{\mathrm{A}}(\mathrm{s})$ para o controlador PID. 
Fonte: Resultados da pesquisa.

A partir da Figura 10, foi possível observar que o sistema de controle em malha fechada para a variável vazão de água alcançou uma certa estabilidade com o passar do tempo para os controladores P e PI, embora esse tempo seja um pouco diferente para cada um deles, respectivamente, $8 \mathrm{~s}, 6 \mathrm{~s}$ e $10 \mathrm{~s}$.

Apesar de o controlador P estabilizar o comportamento da temperatura do pré-condensador, é importante lembrar que este não é, necessariamente, a condição de estabilidade que se deseja para ela. De acordo com a Figura 10, o controlador P estabiliza a temperatura do pré-condensador entre 351,6000 e 351,6002 K. Uma vez que o setpoint é 351,5993 K, esta temperatura final está um pouco acima do valor desejado (offset).

Somente os controladores PI e PID foram capazes de manter a temperatura do précondensador no valor desejado (setpoint) de 351,5993 K. Porém, o controlador PID apresentou um comportamento diferente dos demais logo nos primeiros segundos da simulação. Entretanto, com o passar do tempo, há uma acumulação de informações e ele, o controlador PID, encaminha o processo para um comportamento estável de acordo com o setpoint do processo. Já eram previstos valores destoantes para os controladores PI e PID. Entretanto, no controlador PI essa variação inicial foi menor, uma vez que esse controlador baseia a sua ação de controle na ação proporcional e integral somente.

Dessa maneira, o que melhor desempenhou a sua função foi o controlador PI, pois ele foi capaz de estabilizar o processo com uma pequena variação da temperatura do pré-condensador e menor tempo.

\subsubsection{Razão de refluxo}

Assim como para as demais variáveis, foi possível obter todos os valores de $\mathrm{K}$ da primeira coluna da matriz de Routh para o sistema de controle em malha fechada para a variável razão de refluxo. De todos eles, escolheu-se o valor de K que faz com que todos os elementos da primeira coluna da matriz de Routh sejam positivos e, consequentemente, o processo seja estável. Esse valor é chamado de ganho último $\left(\mathrm{K}_{\mathrm{U}}\right)$ e é mostrado na Tabela 9.

Tabela 9: Ganho último para a função de transferência $G_{R}(s)$.

$\begin{array}{cc}\text { Função de transferência } & \text { Ganho último }\left(K_{U}\right) \\ G_{R}(s)=\frac{-0,0009891 s^{3}-0,007051 s^{2}-0,01278 s-0,05351}{s^{4}+9,497 s^{3}+47,06 s^{2}+116,4 s+278,5} & 4.683,7618\end{array}$

A partir do valor de $\mathrm{K}_{\mathrm{U}}$, calculou-se o valor do período último $\left(\mathrm{P}_{\mathrm{U}}\right)$. Para isso, considerouse a equação característica elementar de um sistema de controle em malha fechada: $1+\mathrm{G}_{\mathrm{P}}(\mathrm{s}) \mathrm{G}_{\mathrm{C}}(\mathrm{s})$ $=0$, onde $\mathrm{G}_{\mathrm{P}}(\mathrm{s})=\mathrm{G}_{\mathrm{V}}(\mathrm{s})$ e $\mathrm{G}_{\mathrm{C}}(\mathrm{s})=\mathrm{K}_{\mathrm{U}}$ (função de transferência do controlador $\mathrm{P}$ ). Do mesmo modo, após manipulações matemáticas, obteve-se a seguinte equação no domínio s e em função de $\mathrm{K}_{\mathrm{U}}$ : 
ISSN: $1415-7314$

ISSN online: $2317-6717$

$$
\begin{gathered}
s^{4}+9,497 s^{3}+47,06 s^{2}+116,4 s+278,5+\left(-0,0009891 s^{3}-0,007051 s^{2}-0,01278 s\right. \\
-0,05351) k_{u}=0
\end{gathered}
$$

Da mesma maneira, utilizou-se o método da substituição direta para simplificar o grau de complexidade da equação acima. Logo, substituindo $s$ por $\omega i$ e considerando que $i^{2}=-1$ obtém-se:

$$
\begin{gathered}
\omega^{4}-9,497 \omega^{3} \mathrm{i}-47,06 \omega^{2}+116,4 \omega \mathrm{i}+278,5+\left(+0,0009891 \omega^{3} \mathrm{i}+0,007051 \omega^{2}\right. \\
-0,01278 \omega \mathrm{i}-0,05351) \mathrm{k}_{\mathrm{u}}=0
\end{gathered}
$$

De maneira análoga, para que a equação característica complexa acima seja igual a zero, é necessário que a sua parte real e imaginária sejam também iguais a zero.

Parte real:

$$
\left.\omega^{4}-47,06 \omega^{2}+278,5+0,007051 \omega^{2} k_{u}-0,05351 k_{u}\right)=0
$$

Parte imaginária:

$$
\left(-9,497 \omega^{3}+116,4 \omega+0,0009891 \omega^{3} k_{u}-0,01278 \omega k_{u}\right) i=0
$$

Considerando que $\mathrm{K}_{\mathrm{U}}$ é igual a $4.683,7618$ e que $\omega$ é a frequência angular, a qual é calculada através da equação $\omega=2 \pi / \mathrm{P}_{\mathrm{U}}$, obtém-se a Tabela 10 com os valores do ganho último $\left(\mathrm{K}_{\mathrm{U}}\right)$ e do período último de oscilação $\left(\mathrm{P}_{\mathrm{U}}\right)$ para o sistema de controle em malha fechada para a variável manipulada razão de refluxo.

Tabela 10: Valores de $K_{U}$ e $P_{U}$ para a função de transferência $G_{R}(s)$. Ganho último $\left(\mathrm{K}_{\mathrm{U}}\right)$ 4.683,7618 $-1,8416$

A partir dos valores do ganho último $\left(\mathrm{K}_{\mathrm{U}}\right)$ e do período último $\left(\mathrm{P}_{\mathrm{U}}\right)$ obtiveram-se os parâmetros dos controladores P, PI e PID $\left(K_{P}, \tau_{I}\right.$ e $\left.\tau_{D}\right)$ por meio das correlações de Ziegler e Nichols, os quais são mostrados na Tabela 11.

Tabela 11: Parâmetros dos controladores para a função de transferência $G_{R}(s)$.

\begin{tabular}{cccc}
\hline Controlador & $\mathrm{K}_{\mathrm{P}}$ & $\tau_{\mathrm{I}}$ & $\tau_{\mathrm{D}}$ \\
\hline P & $2.341,8809$ & - & - \\
PI & $2.128,9826$ & $-1,5346$ & - \\
PID & $2.755,1540$ & $-0,9208$ & $-0,2302$ \\
\hline
\end{tabular}

Da mesma maneira, com os valores de $K_{P}, \tau_{I}$ e $\tau_{D}$ da Tabela 11, foi possível obter o comportamento gráfico da temperatura $(\mathrm{K})$ do pré-condensador em função do tempo (s) para a variável manipulada razão de refluxo. Tal comportamento foi conseguido para o sistema de controle em malha fechada dotado dos controladores P e PI (Figura 12) e PID (Figura 13). 


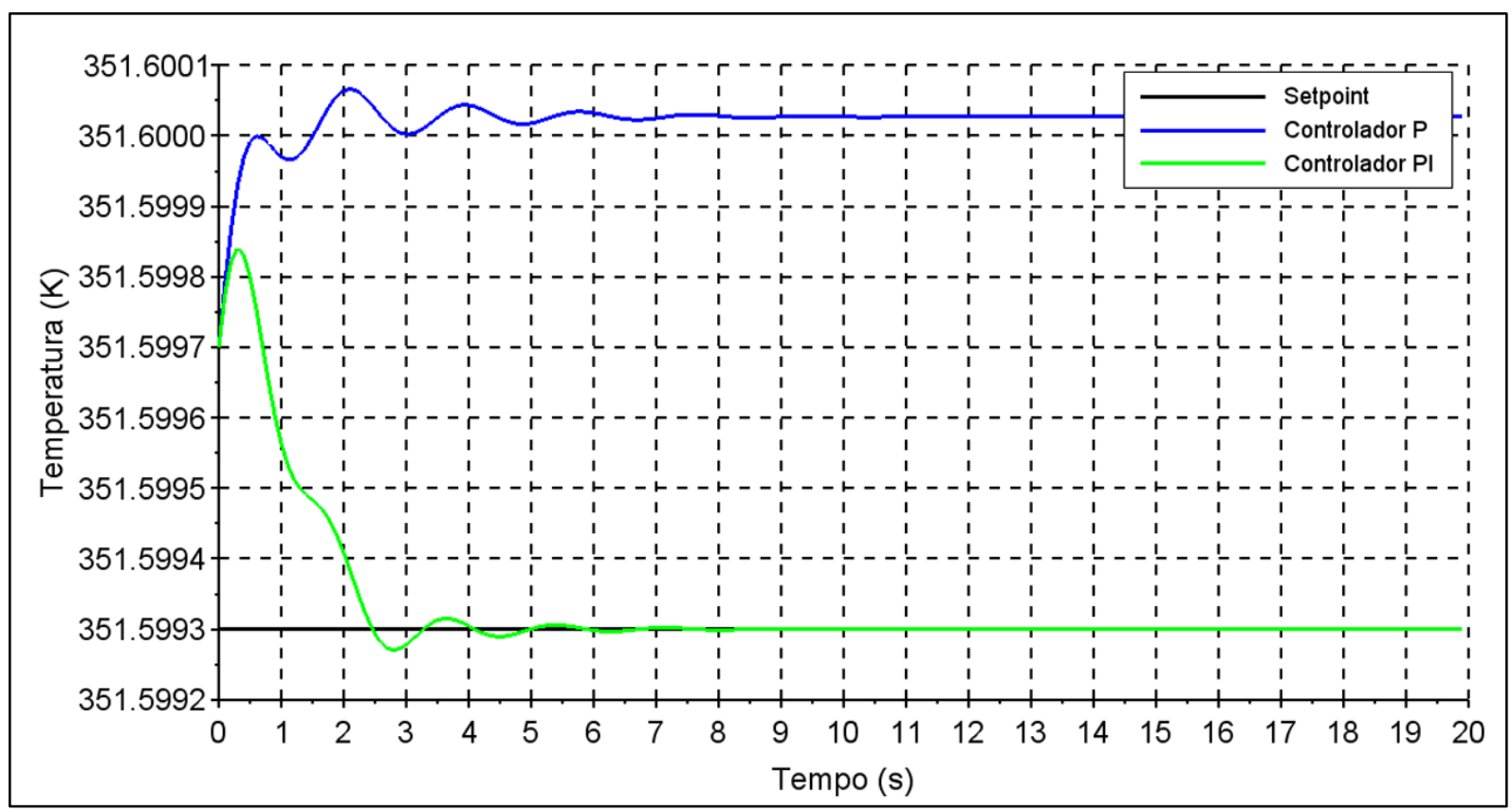

Figura 12: Saída do sistema de controle de $\mathrm{G}_{\mathrm{R}}(\mathrm{s})$ para os controladores $\mathrm{P}$ e PI. Fonte: Resultados da pesquisa.

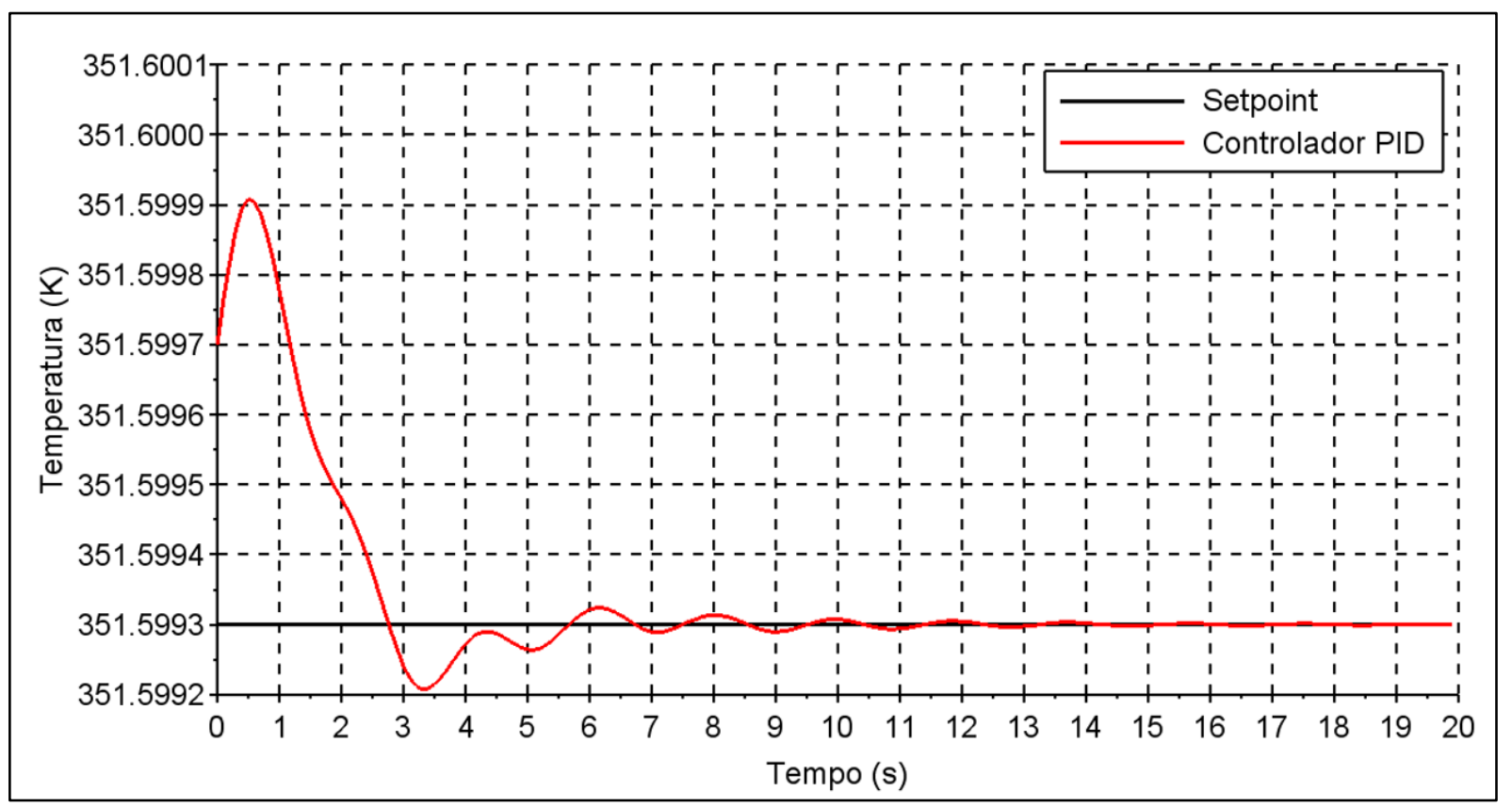

Figura 13: Saída do sistema de controle de GR(s) para o controlador PID. Fonte: Resultados da pesquisa.

A partir da Figura 12 e Figura 13, foi possível observar que o sistema de controle em malha fechada para a variável razão de refluxo atingiu uma estabilidade com o decorrer do tempo para os controladores P, PI e PID, embora esse tempo seja diferente para cada um deles (12 s, $8 \mathrm{~s}$ e $16 \mathrm{~s}$ respectivamente).

De acordo com a Figura 12, o controlador P estabiliza a temperatura do pré-condensador entre 351,6000 e 351,6001 K. Considerando que o setpoint do processo é 351,5993 K, esta temperatura final está um pouco acima do valor desejado. Esse desvio pode parecer pequeno, mas 
ele é extremamente importante para o sucesso da operação de separação, pois a partir dessa temperatura (351,5993 K) há a formação de azeótropo entre o etanol e a água, o que impossibilita a obtenção do etanol do hidratado na concentração desejada.

Somente os controladores PI e PID foram capazes de manter a temperatura do précondensador no valor desejado (setpoint) de 351,5993 K. Da mesma maneira, o que melhor desempenhou a sua função foi o controlador PI, pois foi capaz de estabilizar o processo com uma pequena variação da temperatura do pré-condensador e com um menor tempo.

\section{Conclusão}

O presente trabalho simulou o controle de uma coluna de destilação descontínua utilizando o software Scilab. Para isso, foram analisadas a estabilidade e o comportamento dinâmico do processo através de dois sistemas de controle, um em malha aberta (sem controlador) e o outro em malha fechada (com controlador).

Com isso, foi possível concluir que o sistema de controle em malha aberta para $G_{\mathrm{V}}(\mathrm{s})$, $\mathrm{G}_{\mathrm{A}}(\mathrm{s})$ e $\mathrm{G}_{\mathrm{R}}(\mathrm{s})$ apresentou um comportamento estável mesmo após sofrer uma perturbação degrau nas variáveis de entrada vazão de vapor, vazão de água e razão de refluxo. Porém, esse comportamento estável não é a condição que se deseja para a destilação em questão, a qual deve ocorrer na temperatura máxima de 351,5993 K para que não haja a formação de uma mistura azeotrópica entre o etanol e água. Já para o sistema de controle em malha fechada, isto é, com os controladores P, PI e PID, foi possível concluir que esse sistema de controle apresentou um comportamento estável e foi capaz de manter a temperatura do pré-condensador no valor desejado de 351,5993 K quando dotado dos controladores PI e PID.

O controlador P não foi eficiente no controle da temperatura do pré-condensador, pois apresentou um desvio (offset) entre os valores desejados $(351,5993 \mathrm{~K})$ e medidos para a temperatura do pré-condensador em todas as situações estudas. Esse desvio já era esperado, pois é um erro característico desse controlador. O controlador PI apresentou excelentes resultados, pois foi capaz de estabilizar a temperatura do pré-condensador no valor desejado de 351,5993 K em pouco tempo e eliminar o offset visto para o controlador P. O controlador PID foi capaz de estabilizar a temperatura do pré-condensador, porém, apresentou maiores variações e precisou de mais tempo do que o controlador PI. Isto porque, o controlador PID emprega, além da ação de controle proporcional, a ação integral e a derivativa. Dessa maneira, a melhor estratégia de controle encontrada para a coluna de destilação descontínua avaliada, para $G_{V}(s), G_{A}(s)$ e $G_{R}(s)$, é a que utiliza o sistema de controle em malha fechada com o controlador PI.

\section{Referências}

ADEL, I. M.; ELAMVAZUTHI, I.; HANIF, N. H. H. B. M. Monitoring and controlling system for binary distillation column. Student Conference on Research and development, p. 453 - 456, 2009. 
BARROSO-MUÑOZ, F. O.; HERNÁNDEZ, S.; OGUNNAIKE, B. Analysis of design and control of reactive thermally coupled distillation sequences. 17. th. European Symposium on Computer Aided Process Engineering, p. 877 - 882, 2007.

BAYER, F. M.; ARAÚJO, O. C. B. Controle automático de processos. Disponível em: <http://redeetec.mec.gov.br/images/stories/pdf/eixo_ctrl_proc_indust/tec_autom_ind/ctrl_auto_pro c/161012_contr_aut_proc.pdf >. Acesso em: 18 jun. 2014.

BRAVO, C. O. A. Desenvolvimento de um simulador e controle preditivo de uma coluna de destilação piloto. 2005. 126 f. Dissertação (Mestrado em Engenharia Elétrica) - Programa de Pósgraduação em Engenharia Elétrica, Universidade Federal de Santa Catarina. 2005.

CAMPOS, F. F. Fundamentos de Scilab. Disponível em:<http://www.ime.unicamp.br/ encpos/VIII_EnCPos/Apostila_Scilab.pdf >. Acesso em: 26 abr. 2014.

CAMPOS, M. C. M. M.; TEIXEIRA, H. C. G. Controles típicos de equipamentos e processos industriais. 2. ed. São Paulo: Editora Blucher, 2010. 396 p.

CUNHA, A. P. Automação e controle "on-line" de uma coluna de destilação em batelada. 1996. 128f. Dissertação (Mestrado em Engenharia Química) - Faculdade de Engenharia Química, Universidade Estadual de Campinas. 1996.

FOUST, A. S. et al. Princípios das operações unitárias. 2. ed. Rio de Janeiro: Editora LTC, 2008.

FREITAS, P. J. Introdução à modelagem e simulação de sistemas: com aplicações em Arena. 2. ed. Editora Visual Books, 2008. 372 p.

KETZER, F. Modelagem, simulação e controle de uma coluna de destilação descontínua apropriada à produção de etanol em pequena escala. 2013. $123 \mathrm{f}$. Dissertação (Mestrado em Engenharia de Produção) - Universidade Federal de Santa Maria. 2013.

LUYBEN, W. L. Process modeling, simulation, and control for chemical engineers. 2. ed. Singapore: McGraw-Hill Publishing Company, 1990.

MENEGUELO, A. P. Contribuições à análise e modelagem de operações transientes de colunas de destilação. 2007. 161 f. Tese (Doutorado em Engenharia Química) - Universidade Federal de Santa Catarina. 2007.

NUNES, G. C.; MEDEIROS, J. L.; ARAÚJO, O. Q. F. Modelagem e controle na produção de petróleo: aplicações em Matlab. São Paulo: Editora Blucher, 2010.

PIRES, P. S. M. Introdução ao Scilab: versão 3.0. Disponível em: <http://www.dca.ufrn.br/ pmotta/sciport-3.0.pdf >. Acesso em: 26 jun. 2014.

SCILAB. Versão 5.4.1: Scilab Enterprises, 2014. PC, Windows XP ou mais avançado.

SILVA, E. M.; CUNHA, J. P. V. S. Scilab, Scicos e Rltool: softwares livres no ensino de engenharia elétrica. Disponível em: < http://www.lee.eng.uerj.br/ elaine/501.pdf>. Acesso em: 26 jun. 2014.

STAUDT, P. B. Modelagem e simulação dinâmica de colunas de destilação. 2007. $124 \mathrm{f}$. Dissertação (Mestrado em Engenharia Química) - Escola de Engenharia, Universidade Federal do Rio Grande do Sul. 2007.

STEPHANOPOULOS, G. Chemical process control: an Introduction to heory and practice. New Jersey: Prentice-Hall, 1984. 